\title{
AREND, Sabine, Zwischen Bischof und Gemeinde. Pfarrbenefizien im Bistum Konstanz vor der Reformation
}

Odile Kammerer

\section{OpenEdition}

Journals

Édition électronique

URL : http://journals.openedition.org/ifha/957

DOI : $10.4000 /$ ifha. 957

ISSN : 2198-8943

Éditeur

IFRA - Institut franco-allemand (sciences historiques et sociales)

Référence électronique

Odile Kammerer, "AREND, Sabine, Zwischen Bischof und Gemeinde. Pfarrbenefizien im Bistum Konstanz vor der Reformation", Revue de l'IFHA [En ligne], Date de recension, mis en ligne le 01 janvier 2004 consulté le 22 septembre 2020. URL : http://journals.openedition.org/ifha/957 ; DOI : https://doi.org/ 10.4000/ifha.957

Ce document a été généré automatiquement le 22 septembre 2020.

(C)IFHA 


\title{
AREND, Sabine, Zwischen Bischof und Gemeinde. Pfarrbenefizien im Bistum Konstanz vor der Reformation
}

\author{
Odile Kammerer
}

1 Soutenue en 2001, l'habilitation de S.A. s'inscrit dans la série des publications sur l'histoire régionale du sud-ouest de l'Allemagne, même si son impact géographique dépasse très largement cet espace. L'objet de l'étude, en effet, porte sur le bas clergé dans le plus grand diocèse de l'Empire, celui de Constance qui recouvrait trois diocèses actuels sur trois pays : le Bade-Württemberg, le sud de la Bavière, la Suisse alémanique et l'ouest du Vorarlberg, soient 350 abbayes, 1760 paroisses et environ 17000 prêtres. L'immensité relative de ce territoire diocésain suscite au moins deux traits caractéristiques : d'une part la gestion difficile à une si grande échelle a poussé l'administration diocésaine à la mise au point précoce d'une comptabilité organisée, régulière et rigoureuse dont la chancellerie pontificale a servi de modèle, et d'autre part les diversités ou particularismes, surtout dans la partie suisse du diocèse, ont pu émerger de plus en plus clairement.

2 L'exceptionnel corpus produit et conservé par ce diocèse autorise une enquête elle aussi presque exceptionnelle par sa thématique : les conditions de vie et de travail du bas clergé. L'historiographie allemande et suisse offre, en effet, de nombreuses enquêtes institutionnelles sur les diocèses et les paroisses mais encore très peu sur le personnel ecclésiastique. La bibliographie fort riche de ce travail pionnier se trouve être presque exclusivement germanique pour deux bonnes raisons. L'enquête porte sur un espace particulier, celui de l'Église d'Empire. D'autre part, ailleurs, en France par exemple, le matériau disponible (chartes épiscopales, écrits canoniques, statuts synodaux etc.) et la tendance historiographique poussent les historiens vers l'étude de la vie religieuse, du gouvernement central de l'Église ou de l'histoire des diocèses et paroisses. La perspective ici est tout autre : grâce à un dépouillement et un traitement informatique des registres comptables tenus par l'administration diocésaine sur plus de deux siècles (et édités pour l'essentiel à la fin du XIXe s.), S.A. propose une synthèse, 
tableaux statistiques à l'appui, permettant d'établir qui participait à cette économie générale des bénéfices et comment : les collateurs et les bénéficiaires, vaste réseau entre paroissiens et évêque.

3 La présentation des sources occupe une place de choix (p. 6-38) visant à la validation de l'enquête mais surtout servant d'élément démonstratif de la thèse. En dépit de son vaste territoire, le diocèse de Constance ne dispose que d'un temporel très réduit, initié par les abbés de Saint-Gall et de la Reichenau, évêques aux VIIIe et IXe s., mais par la suite bridé par la concurrence avec les Habsbourg. Ne pouvant compter sur son " domaine ", l'évêque n'a pas d'autres ressources que les taxes sur les bénéfices en tant que biens matériels et revenus attachés à la fonction exercée. On comprend alors la production performante et massive de registres d'une administration comptable destinée à la perception efficace de ces revenus par les receveurs diocésains mais aussi à la réponse aux tensions ou conflits avec un clergé sourcilleux ou franchement récalcitrant. À l'origine des premiers registres de bénéfices (sur parchemin) se trouve l'organisation pontificale de la levée des décimes pour la croisade par Grégoire X en 1274. Il s'agissait d'enregistrer et de contrôler la perception du vingtième puis du dixième des bénéfices. Le livre des décimes du diocèse de Constance débute en 1275, bientôt suivi du livre des " quartae " ou perception par l'évêque du quart des dîmes paroissiales, et de celui des amendes perçues par les curés (bannales). Si la conservation jusqu'au XIVe s. reste lacunaire, elle devient systématique au XVe s. et permet d'établir des études sérielles.

4 S.A. s'interroge d'abord, à l'échelle de la paroisse, sur les revenus divers attachés aux bénéfices, contribuant à définir la place du prêtre au milieu de ses paroissiens, avant d'aborder ce qui doit être reversé à l'évêque, autre tension relationnelle très forte, pour enfin parvenir à l'analyse de la composition de cette société de bénéficiaires. Le bénéfice, au cœur de l'étude, ne se présente pas sous forme de salaire mais d'une mise à disposition pour exploitation d'un bien foncier exempt de redevance (temporalia), à quoi s'ajoutent la dîme et les offrandes, le casuel et autres revenus (spiritualia). Le produit de la dîme, progressivement étendue des fruits de la terre au bétail et à ses produits, ne revient que pour un tiers au curé, un tiers allant à l'évêque et un tiers à la fabrique. Si le bénéficiaire est empêché d'assurer ses fonctions, il cède alors à un desservant une partie de ses revenus, ce qui se produit dans la moitié des bénéfices au milieu du XIVe s. Cette portion congrue est au gré du curé, mais elle correspond en moyenne à un tiers des revenus. En réalité, le patron du bénéfice perçoit environ les deux tiers. Le bas clergé ne vit donc pas de la dîme. Au milieu du XIVe s., sur 100 paroisses souabes, les bénéficiaires ne reçoivent effectivement qu'une minime partie de la dîme, mais $70 \%$ des revenus globaux de la paroisse : les offrandes, les quêtes, le casuel etc., gamme beaucoup plus variée que dans les autres diocèses. L'exploitation de ces résultats à l'échelle du diocèse et leur analyse masquent cependant quelque peu la différentiation entre paroisses rurales et paroisses urbaines, sauf à consulter attentivement les tableaux. En ville, en effet, la prépondérance des revenus provient des offrandes en raison des nombreuses fondations. On y guette également la rivalité bien connue avec les Mendiants, mais la typologie des sources étudiées ne permet d'aborder que de biais, par le système de l'incorporation, ce problème aigu en dehors de l'Église d'Empire. À partir du XIIe s., sous la pression des anciens établissements ecclésiastiques dépossédés de leur service paroissial, se multiplient les paroisses incorporées qui réunissent un bénéfice avec charge d'âmes au patrimoine d'un établissement ecclésiastique. Y sont nommés des vicaires qui perçoivent le plus souvent 
une portion congrue en nature à hauteur de un cinquième à un tiers du total des revenus. Un trait caractéristique de la partie suisse du diocèse concerne l'entretien du sacristain : ce sont les paroissiens eux-mêmes qui partagent offrandes et casuel entre le pasteur et le sacristain. L'analyse du montant et de la variation de ces revenus paroissiaux permet à S.A. de conclure que la majorité des bénéficiaires a assez pour vivre et même plus. Le prêtre assume des responsabilités de proximité qui dépassent le seul cadre religieux. Sachant lire et écrire, il est amené assez souvent, dans les paroisses rurales, à jouer les rôles de notaire et maître d'école. Cette large participation à la vie de la communauté incite celle-ci à exercer un droit de regard sur la moralité et les qualités de celui qui assure la fonction de prêtre.

5 Le bas clergé, qui peut assumer dignement son rôle, reverse pourtant une part considérable de ses revenus à l'évêque en raison de son droit d'imposition reconnu dès le XIIe s. À son entrée en charge, lors de la collation de la charge d'âmes, le bénéficiaire verse les annates, une sorte de droit recognitif de son investiture. Pour la perception de cette taxe, l'administration diocésaine se révèle performante puisque aucune investiture ne lui échappe. Puis, chaque année, le bénéficiaire doit s'acquitter de la quarte (un quart de la dîme), taxe liée aux visites pastorales et frais de chancellerie. Le produit des amendes est versé à la Saint Martin et une autre imposition dite Konsolatio à la Saint André. À ces taxes annuelles s'ajoute une taxe exceptionnelle, le subsidium charitatum, pour pallier l'endettement chronique de l'évêque. À partir du XVe s., cette taxe est exigée dès l'intronisation (les élections épiscopales coûtent cher !) et réitérée régulièrement pour un montant de plus en plus élevé, car les taxes «normales " ne suffisent jamais à éteindre la dette. L'opposition résolue du clergé suisse se manifeste alors clairement pour s'y soustraire. Parallèlement à cette tendance à l'augmentation des taxes, on constate une rationalisation et un effort de gestion pour répondre aux nombreux conflits dans un diocèse trop étendu pour que l'administration diocésaine soit vraiment efficace.

6 Après avoir décortiqué le système bénéficial, S.A. s'interroge sur les personnes, les patrons et les bénéficiaires. Les patrons, comme dans le plupart des diocèses d'Empire, sont pour moitié des laïcs, pour moitié des institutions ecclésiastiques. Les communes concourent également à la présentation, même si le droit canon ne le prévoit pas. De plus en plus au XVe s., la nomination du curé, et surtout celle du desservant, intéresse les paroissiens qui attendent de lui une pastorale solide, la distribution des sacrements, la célébration régulière de l'Eucharistie et surtout la résidence. Qui sont donc ces bénéficiaires? Les conditions canoniques d'obtention d'un bénéfice (âge, tonsure, bonne moralité) sont respectées au XVe s. puisque $85 \%$ des bénéficiaires sont des prêtres. Une exception aux conditions habituellement requises : la naissance illégitime n'est jamais un obstacle. La qualification pastorale s'acquiert "sur le tas " chez un curé de campagne comme l'apprenti chez son maitre. La qualification intellectuelle, qui ne concerne que $10 \%$ des bénéficiaires, s'acquiert, elle, à l'université et ouvre l'accès aux bénéfices les plus rentables. Mais un des intérêts majeurs de l'enquête de S.A. est de mettre en valeur la nécessité, pour être présenté par un patron à un bénéfice, d'appartenir à un réseau de clientèle. Les relations sociales jouent un rôle essentiel, l'emportant même sur les avantages financiers. Sur ce point également, les fidèles suisses affirment leur différence en exerçant un droit de participation au choix de leur prêtre et en privilégiant ses qualités de pasteur. La mobilité est la règle : deux tiers restent moins de dix ans dans les mains d'un même titulaire et encore deux tiers entre un à cinq ans. Il est intéressant de constater que $63 \%$ des bénéfices « tournent » par un 
jeu volontaire favorisé par les relations sociales ou/et, pour les plus jeunes, par le désir de faire carrière en acceptant des responsabilités. $20 \%$ des bénéfices résultent d'un simple échange.

7 Une image nuancée du bas clergé dans le diocèse de Constance apparaît dans ce travail en contrepoint des noirs tableaux du même clergé en France ou le diocèse de Genève par exemple. Les bénéfices en Allemagne résistent mieux qu'ailleurs à la crise de la conjoncture et des structures qui les ruinent et qui entraînent l'indécence, le cumul nécessaire et l'absentéisme des titulaires. Les bénéficiaires dans le diocèse de Constance et, de plus en plus, leurs desservants, s'insèrent au cœur de la communauté des fidèles, attentifs à leurs qualités pastorales et soucieux de leur place d'hommes du livre et de l'écriture. Le cas suisse apparaît nettement dans le rapport de force entre paroissiens patrons et évêque. Les fidèles tiennent au choix effectif de leur pasteur même s'ils en changent chaque année, tout comme ils le font pour leur berger. Le bas clergé au cœur de la paroisse connaît une vie décente en dépit des ponctions régulières et de plus en plus fortes de l'évêque impécunieux. L'intérêt de l'étude réside aussi dans la parfaite maîtrise de deux échelles : l'analyse globale au niveau du diocèse et la vie quotidienne au niveau de la paroisse que l'on voit affleurer dans les nombreux exemples. La population composite que forme ce bas clergé joue un rôle fondamental d'articulation économique et surtout sociale entre paroisse et évêque.

Odile KAMMERER (Université de Mulhouse) 